inflammatory/remodelling process either from current environmental exposure or from a persistent activation of the immune system of undetermined origin.

In a previous study, my colleagues and I reported that atopic subjects with asymptomatic AHR and a family history of asthma, who were chronically exposed to indoor allergens to which they were sensitised (particularly domestic animals), were at higher risk of developing asthma in the near future [2]. Our study documented the changes occurring in the airways when subjects with asymptomatic AHR developed symptomatic asthma. These changes consisted mostly of an increase in airway remodelling and reversal of the CD4+/CD8+ lymphocyte ratio. Although the study included a limited number of subjects, these features were quite striking.

I had a chance to review this topic in recent years and my conclusions were that in some specific subgroups of patients, asymptomatic AHR is associated with an increased risk for the development of asthma [3]. More studies should be performed to define the population in which screening could be beneficial. Unfortunately, when symptomatic asthma develops, airway structural changes, which perhaps explain a large part of the physiological features observed, are largely irreversible and symptoms are persistent. The ideal would be to prevent this condition instead of simply trying to achieve optimal control once developed. In a recent editorial, P.J. Sterk and I suggested that we should try to prevent potentially detrimental airway structural changes, perhaps by controlling triggering mechanisms of the disease at an early stage or by adequately treating conditions associated with an increased risk of developing lower airways diseases (e.g. rhinitis) [4].

The risk of developing asthma is thought to be related to a combination of genetic and environmental factors. AHR per se may not be a predicting factor of asthma but when associated with atopy or a strong family history of asthma, it may indicate that a given subject is closer to the "asthmatic range" of airway responsiveness, and, as suggested in previous studies [2, 3], if exposed to a pro-inflammatory trigger, the subject may develop full-blown asthma in the coming months/years.

A study such as the one by VAN DEN NIEUWENHOF et al. [1] is welcome in terms of improving knowledge about the significance of airway hyperresponsiveness, but much remains to be determined if we are to more accurately identify those at risk of developing asthma in the near future and those who would benefit from early intervention for the prevention of asthma. The suggestion that screening for asymptomatic airway hyperresponsiveness cannot be generally recommended seems appropriate in the population studied but even then, it should not prevent investigation of the possibility that specific high-risk groups could be identified early and become candidates for preventative measures in order to try to avoid the development of symptomatic asthma. With regard to atopy as a risk factor of asthma, only a minority will develop asthma in the future and more emphasis should be placed upon finding ways to identify allergic subjects at high risk to develop asthma.

\section{L-P. Boulet}

Research Centre, Laval Hospital, Cardiology and Pneumology Institute of Laval University, Québec, QC, Canada.

\section{STATEMENT OF INTEREST}

A statement of interest for L-P. Boulet can be found at www.erj.ersjournals.com/misc/statements.shtml

\section{REFERENCES}

1 van den Nieuwenhof L, Schermer T, Heijdra Y, et al. Are asymptomatic airway hyperresponsiveness and allergy risk factors for asthma? A longitudinal study. Eur Respir J 2008; 32: 70-76.

2 Laprise C, Laviolette M, Boutet M, Boulet LP. Asymptomatic airway hyperresponsiveness: relationships with airway inflammation and remodelling. Eur Respir J 1999; 14: 63-73.

3 Boulet LP. Asymptomatic airway hyperrresponsiveness. A curiosity or an opportunity to prevent asthma? Am J Respir Crit Care Med 2003; 167: 371-378.

4 Boulet LP, Sterk PJ. Airway remodelling: the future. Eur Respir J 2007; 30: 831-834.

\title{
The effect of inhaled lidocaine-hydrofluoroalkane 134a in prednisone-dependent eosinophilic bronchitis
}

\section{To the Editors:}

We report on the preliminary findings with inhaled lidocaine in patients with eosinophilic airway inflammation, identified by sputum cell counts (eosinophilic bronchitis), with or without asthma, who are prednisone dependent. Lidocaine has been shown to possess anti-eosinophil [1,2] and anti-spasmodic [1, 3] actions, as well as steroid-sparing efficacy $[4,5]$. However, the anti-eosinophil effects have not been demonstrated in humans in vivo. Furthermore, the delivery of lidocaine by nebulisation, as utilised in previous clinical studies $[4,5]$, makes the treatment inconvenient. Therefore, we synthesised a preparation of lidocaine in a hydrofluoroalkane (HFA)134a, pressurised metered-dose inhaler (MDI) and investigated the prednisonesparing and anti-eosinophilic effects.

Five patients requiring daily prednisone in addition to highdose inhaled corticosteroid to treat eosinophilic bronchitis 
(fig. 1) were randomised in a double-dummy, crossover study to add-on lidocaine or HFA134a MDI placebo. After 4 weeks, the prednisone dose was reduced monthly by $5 \mathrm{mg}$ until either a loss in symptom control or the prednisone dose was discontinued for 1 month. All subjects had been unable to reduce prednisone without an eosinophilic exacerbation (sputum eosinophils $>3 \%$ ) in the previous 12 months. At entry, all patients were clinically stable, four had current asthma and all had airflow limitation despite being nonsmokers (table 1). There were no other comorbidities or exposure to seasonal allergies throughout the present study. The lidocaine dose $\left(3 \mathrm{mg} \cdot \mathrm{puff}^{-1}\right.$, mass median aerodynamic diameter of $3.5 \mu \mathrm{m}$, fine particle $(\leqslant 4.7 \mu \mathrm{m}$ aerodynamic diameter) fraction of 75\%; ex-Aerochamber Plus; TMI, London, ON, Canada) was $12 \mathrm{mg}$ four-times daily approximating the nebulised therapies in previous studies (assuming a mid-range lung deposition efficacy of $7.5 \%$ for the PARI LC Plus nebuliser (PARI Respiratory Equipment Inc., Richmond, VA, USA)) [4, 5]. Clinical exacerbations were treated according to standard practice until symptoms, forced expiratory volume in one second (FEV1) and prednisone dose returned to baseline for 1 month, before crossing over to the other treatment. At each visit, spirometry, blood eosinophils, post-dosing blood-lidocaine levels and induced-sputum cell counts were assessed [6].

The study was prematurely terminated because of frequent exacerbations and side-effects related to lidocaine. All patients received lidocaine but only two patients (patients 1 and 2) completed both treatment arms (table 2; fig. 1). Placebo treatment resulted in greater reduction in prednisone dose and clinical exacerbations were associated with sputum eosinophilia (table 2). In contrast, lidocaine therapy was associated with an early onset of exacerbations characterised by increases in sputum total cell counts (patients 1, 2 and 5), which were predominantly neutrophilic (patients 2 and 4) or mixed neutrophilic and eosinophilic (patients 1 and 5).

Adverse effects, related to lidocaine, included oropharyngeal numbness and a bitter taste and were reported in all patients. Two patients (patients 2 and 3) developed cough, throat tightness and dyspnoea post-dosing without impairment in FEV1 or expiratory flow volume curves, which was considered to be due to laryngeal dysfunction. This led to one patient withdrawing from the study (patient 3). Lidocaine-induced bronchoconstriction occurred in one patient (patient 1) and coincided with loss of asthma control.

We speculate that the absence of clinical and anti-inflammatory effects of lidocaine presented here was due to the highly selective population studied. Our patients demonstrated current sputum eosinophilia and responsiveness to prednisone, whereas the inflammatory phenotype of the cohorts from previous studies was not known $[4,5,7]$. Given the heterogeneity in asthma, these cohorts may comprise of noneosinophilic phenotypes that are less steroid responsive. In these subjects, reduction of corticosteroid dose might be expected to be tolerated better without exacerbating airway inflammation. Indeed, there have been subgroups described with scant evidence of inflammation but with an increase in airway smooth muscles $[8,9]$ in whom the antispasmodic property [1,3] of lidocaine would be beneficial. Furthermore, lidocaine may adversely affect lung function in our studied population by increasing basal airway tone (which has been demonstrated in some asthmatics but not in others [10]) or it may have an irritant effect with worsening of airway inflammation. The lack of effect does not seem to be a result of inadequate

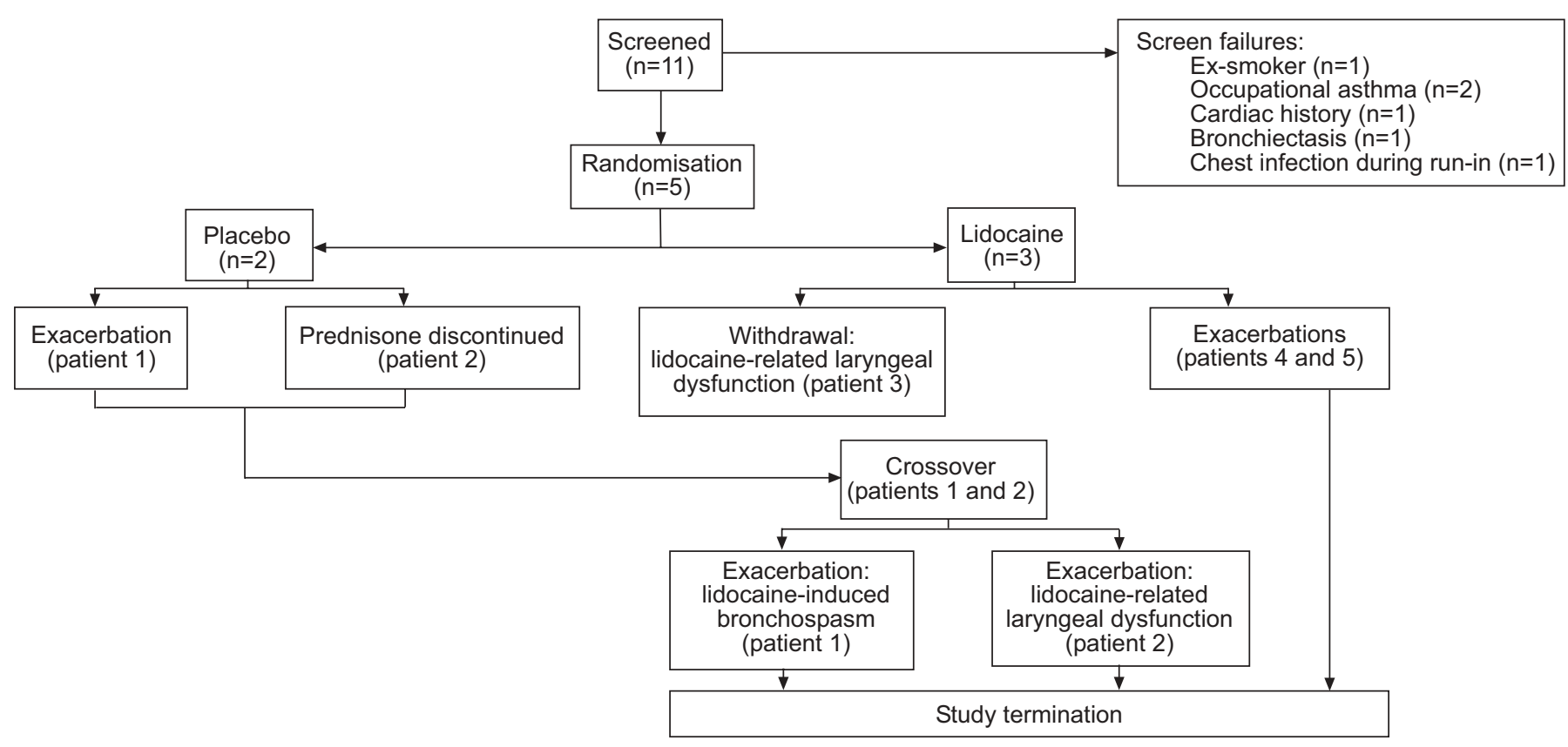

FIGURE 1. Flow chart of the subjects enrolled. Subjects were randomised to either lidocaine $(n=3)$ or placebo $(n=2)$ add-on therapy for 4 weeks, after which prednisone was reduced monthly until either prednisone was discontinued $(n=1)$ or loss of asthma control (lidocaine $n=3$, placebo $n=1$ ) occurred, necessitating the institution of appropriate treatment. Once stable for 1 month, subjects crossed over $(n=2)$ to receive the alternative trial medication. 


\begin{tabular}{|c|c|c|c|c|c|}
\hline & \multicolumn{5}{|c|}{ Patient } \\
\hline & 1 & 2 & 3 & 4 & 5 \\
\hline Sex & M & M & $\mathrm{F}$ & M & M \\
\hline Age yrs & 51 & 50 & 67 & 70 & 42 \\
\hline Duration of asthma yrs & 7 & 7 & 19 & 20 & 8 \\
\hline$\Delta$ FEV1 mL (\%) ${ }^{\#}$ & $280(15)$ & $130(5)$ & $200(14)$ & $320(14)$ & $400(12)$ \\
\hline Methacholine $\mathrm{PC}_{20} \mathrm{mg} \cdot \mathrm{mL}^{-1}$ & 2 & 0.96 & $>8$ & NA & 32 \\
\hline Duration of prednisone treatment yrs & 7 & 2.5 & 19 & 7 & 3 \\
\hline Other asthma therapies $\mu \mathrm{g} \cdot \mathrm{day}^{-1}$ & FP 2000 , S 100 & BUD 1600 & FP 2000 , S 100 & FP 2000 & FP1000, MONT \\
\hline
\end{tabular}

Spirometry values were recorded post-bronchodilation. FEV1: forced expiratory volume in one second; \% pred: \% predicted; VC: vital capacity; PC20: provocative

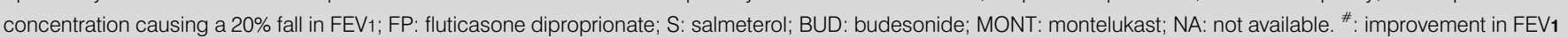
after $200 \mu \mathrm{g}$ salbutamol, withholding long- and short-acting $\beta_{2}$-agonists for 48 and $8 \mathrm{~h}$, respectively.

dosing or of poor adherence to lidocaine therapy, since lidocaine metabolites were detectable post-dosing and all patients complained of oropharyngeal numbness and bitter taste.

In conclusion, we found lidocaine-hydrofluoroalkane 134a metered-dose inhaler therapy was poorly tolerated and did not demonstrate prednisone-sparing or inhibit eosinophilic inflammation in prednisone-dependent patients with severe eosinophilic bronchitis. Further randomised studies, with careful characterisation of phenotypes, are needed in order to better define its efficacy and role in the management of prednisonedependent asthma.

TABLE 2 Physiological and inflammatory values for each subject at baseline and on the final visit in the study

\begin{tabular}{|c|c|c|c|c|c|c|c|}
\hline & 1 & 2 & 1 & 2 & 3 & 4 & 5 \\
\hline Treatment & $P$ & $P$ & LCN & LCN & LCN & LCN & LCN \\
\hline Weeks of trial drug & 9 & 20 & 6 & 8 & 4 & 6 & 4 \\
\hline \multicolumn{8}{|l|}{ Prednisone dose $\mathrm{mg} \cdot$ day $^{-1}$} \\
\hline \multicolumn{8}{|l|}{ FEV 1 L } \\
\hline Baseline & 2.47 & 2.87 & 2.31 & 3.20 & 1.41 & 2.54 & 3.84 \\
\hline Final & 1.69 & 2.95 & 1.85 & 2.97 & 1.28 & 2.09 & 2.96 \\
\hline \multicolumn{8}{|c|}{ Blood eosinophils $10^{6}$ cells $\cdot \mathrm{mL}^{-1}$} \\
\hline Baseline & 0.02 & 0.4 & 0.2 & 0.2 & 0.2 & 0.8 & 0.6 \\
\hline Final & 0.3 & 1.0 & 0.2 & 0.1 & 0.2 & 0.1 & 0.9 \\
\hline \multicolumn{8}{|l|}{ Sputum TCC $10^{6}$ cells $\cdot \mathrm{mL}^{-1}$} \\
\hline \multicolumn{8}{|l|}{ Sputum eosinophils \% } \\
\hline Baseline & 7.0 & 0.7 & 7.7 & 8.7 & 10.0 & 5.0 & 0.0 \\
\hline Final & 44.3 & 39.3 & 16.5 & 1.3 & NA & 0.3 & 43.3 \\
\hline \multicolumn{8}{|l|}{ Sputum neutrophils \% } \\
\hline Baseline & 62.3 & 34.7 & 60.3 & 38.0 & 25.3 & 41.0 & 75.8 \\
\hline Final & 38.0 & 19.3 & 75.8 & 94.7 & NA & 93.0 & 42.7 \\
\hline Serum lidocaine $\mu \mathrm{g} \cdot \mathrm{mL}^{-1}$ & 0 & 0 & 0.7 & 0.2 & 0.7 & 0.1 & 0.2 \\
\hline
\end{tabular}

FEV1: forced expiratory volume in one second; TCC: total cell count; NA: not available; P: placebo; LCN: lidocaine-hydrofluoroalkane 134a. 
M. Duong*, A.M. Wilson", L. Jayaram*, M. Dolovich* and F. Hargreave*

*Asthma Research Group, Firestone Institute for Respiratory Health, St Joseph's Healthcare and Hamilton Health Sciences, McMaster University, Hamilton, ON, Canada, and "School of Medicine, Health Policy and Practice University of East Anglia, Norwich, UK.

\section{STATEMENT OF INTEREST}

None declared.

\section{ACKNOWLEDGEMENTS}

The authors would like to thank M. Morris, P. Hussack, A. Efthimiadis and S. Evans (The Firestone Institute for Respiratory Health, St Joseph's Hospital, McMaster University, Hamilton, ON, Canada) for their assistance in the conduct of the trial and sputum processing.

\section{REFERENCES}

1 da Costa JC, Olsen PC, de Azeredo Siqueira R, et al. JMF2-1, a lidocaine derivative acting on airways spasm and lung allergic inflammation in rats. J Allergy Clin Immunol 2007; 119: 219-225.

2 Okada S, Hagan JB, Kato M, et al. Lidocaine and its analogues inhibit IL-5-mediated survival and activation of human eosinophils. J Immunol 1998; 160: 4010-4017.
3 Kai T, Nishimura J, Kobayashi S, Takahashi S, Yoshitake J, Kanaide H. Effects of lidocaine on intracellular $\mathrm{Ca}^{2+}$ and tension in airway smooth muscle. Anesthesiology 1993; 78: 945-965.

4 Hunt LW, Swedlund HA, Gleich GJ. Effect of nebulized lidocaine on severe glucocorticoid-dependent asthma. Mayo Clin Proc 1996; 71: 361-368.

5 Hunt LW, Frigas EF, Butterfield JH, et al. Treatment of asthma with nebulized lidocaine: a randomized, placebocontrolled study. J Allergy Clin Immunol 2004; 113: 853-859.

6 Pizzichini E, Pizzichini MMM, Efthimiadis A, et al. Indices of airway inflammation in induced sputum: reproducibility and validity of cell and fluid-phase measurements. Am J Respir Crit Care Med 1996; 154: 308-317.

7 Decco ML, Neeno TA, Hunt LW, O'Connell EJ, Yunginger JW, Sachs MI. Nebulized lidocaine in the treatment of severe asthma in children: a pilot study. Ann Allergy Asthma Immunol 1999; 82: 29-32.

8 Holgate ST, Polosa R. The mechanisms, diagnosis, and management of severe asthma in adults. Lancet 2006; 368: 780-793.

9 Wenzel S. Severe asthma in adults. Am J Respir Crit Care Med 2005; 172: 149-160.

10 Chang HY, Togias A, Brown RH. The effects of systemic lidocaine on airway tone and pulmonary function in asthmatic subjects. Anesth Analg 2007; 104: 1109-1115.

DOI: 10.1183/09031936.00087108

\section{Dental units as infection sources of Pseudomonas aeruginosa}

\section{To the Editors:}

In a recent issue of the European Respiratory Journal, we read with interest the article by SCHELSTRAETE et al. [1] about Pseudomonas aeruginosa in the home environment of newly infected patients with cystic fibrosis (CF). Based on the study results, SCHELSTRAETE et al. [1] suggest that neither home environment nor other patients are important sources of $P$. aeruginosa infection; therefore, the question remains as to the actual source of an initial infection. They conclude that acquisition from the environment outside the home is probable.

One possible source could be aerosol exposition of contaminated water during dental treatment. Transmission of microbial pathogens to patients from water in dental chair units (DCUs) has been a concern for many years. In the early 1980s, a German study revealed $P$. aeruginosa in $74 \%$ (29 out 39 patients) of the investigated DCUs in private dental practices; however, the findings were not widely noticed as it was published in German [2]. Bacterial biofilm formation in DCU waterlines is a widespread problem and poses a potential risk of infection to dental staff and patients, particularly those who are medically compromised, i.e. with CF or immunocompromised [3, 4]. Therefore, different measures of disinfection have been introduced to improve the hygiene in dental units and guidelines for infection control in dental healthcare settings have been published [5]. In spite of these measures, $P$. aeruginos a can still be frequently found in water of DCUs. We have recently investigated the prevalence of $P$. aeruginosa and the total bacterial count (all aerobic mesophilic bacteria measured as colony forming units (CFU)) in the water of DCUs in the area of St. Gallen (Switzerland). In total, water from 76 dental units was collected either from turbine tube, multifunction syringe or micromotor early on a Monday morning before the instruments were used. After using the DCU for $\geqslant 2 \mathrm{~h}$, water was collected for a second time. All specimens were immediately transported to the Environmental Health Department (St. Gallen) and examined within $24 \mathrm{~h}$ of collection, as described in a previous study [6]. P. aeruginosa was found in seven $(9 \%)$ out of 76 DCUs from the first sample collection and only one was negative after using the DCU for $\geqslant 24 \mathrm{~h}$. Increased total bacterial count $\left(>300 \mathrm{CFU} \cdot \mathrm{mL}^{-1}\right)$ was found in $60 \%$ (46 out of 76) of the DCUs in the first probe, which decreased to $38 \%$ (29 out of 76 ) after using the unit for $\geqslant 2 \mathrm{~h}$. Legionella spp. were found in $20 \%$ (15 out of 76 ) of both collected specimens. All dentists gave reassurance that they follow the manufacturers' disinfection recommendations.

The bacteria that contaminate the dental chair unit waterlines can originate from two places. First, municipal water piped 